\title{
EL TRANSPORTE AEREO Y LA EXPO'92
}

\author{
Fernando LOPEZ PEREZ*
}

\section{ASPECTOS PREVIOS}

El presente estudio plantea, la dotación actual de ayudas a la navegación, estructuración del espacio aéreo en el sur peninsular y uso que del mismo se hace, que condicionarán el transporte de personas hacia/desde la Exposición Hispalense. Se contentará poner de relieve todos aquéllos aspectos que incidan negativamente en este apartado.

En todas las publicaciones, seminarios y coloquios de los que tengo noticias, el transporte de personas fuera del recinto de la Muestra no ha sido contemplado. Quizás por no tener competencias en este campo, los responsables de la misma, pero estimo que es un capítulo importantísimo que debe ser estudiado en profundidad, a fin de que en el plazo que aún queda para su inauguración, se den los pasos necesarios para que el previsto volumen de visitantes pueda ser atendido adecuadamente.

En el espacio aéreo del mediodía español existen una serie de connotaciones, poco conocidas, y que no están presentes en el resto del territorio nacional, que pueden restringir, severamente el tráfico aéreo comercial, regular o charter. Estas restricciones, en caso de no ser obviadas, pueden traducirse en flujos de tráfico poco fluidos, lo que redundará negativamente en la imagen de la Exposición Universal.

Se está a tiempo, aún, para que los responsables del Control de Tráfico Aéreo Español por un lado, y el Ministerio de Defensa, por otro, como máximos responsables del Espacio Aéreo Español sienten las bases para que durante la Expo, el tráfico aéreo origen/destino Sevilla encuentre el máximo de facilidades posibles, evitando improvisaciones de última hora.

Para el lego en la materia, la plasmación terrestre del transporte aéreo son los aeropuertos. Evidentemente son necesarias superficies para el aparcamiento de aeronaves, edificios para la atención del pasajero, y buenas comunicaciones terrestres ciudad-aeropuerto. Pero existe toda una infraestructura humana

* Profesor Asociado de Análisis Geográfico Regional. Sevilia. 
y técnica, no apreciable por el común, que permite que esta actividad se lleve a cabo de forma segura, fluida y económica. Si importante es lo primero, vital es lo segundo, ya que de poco serviría un magnífico edifico terminal si el viajero que debe ocuparlo sufre demoras o retrasos de entidad incompatible con aquello que la Exposición quiere transmitir. No debe olvidarse que en el éxito de la misma están implicados todos los sectores nacionales, unos más visibles que otros, y este que vamos a abordar, nos atrevemos a calificarlo de paradigmático.

\subsection{Las previsiones de visitantes a la Expo'92}

No nos interesan, para el presente estudio, más que aquellas personas que, debido a las especiales características de los transportes terrestres españoles en general, y andaluces en particular, utilicen el avión como medio de transporte. No debemos olvidar que los condicionamientos geográficos, y la especial disposición de nuestra red viaria, poco vertebradora del territorio, producto de muy diversas causas, y que no es el momento de entrar en ellas, hacen del transporte aéreo, el único compatible para buena parte de los visitantes nacionales y, fundamentalmente extranjeros (CANO GARCIA, 1986-1988; LOPEZ PEREZ, 1988).

Según las prospecciones realizadas por los responsables de la Muestra Universal, el volumen total de personas que se acercarán a la Exposición superan los 18 millones. Por desgracia, y hasta el momento presente, no se ha plasmado en cifras las modalidades de transporte que utilizaran estos potenciales visitantes.

En el cuadro I hemos obviado todos aquellos cuyos desplazamientos impliquen distancias inferiores a los $300 \mathrm{kms}$. (Extremadura y Andalucía), que presumiblemente se desplazaran en cualquier medio terrestre. Evidentemente tampoco utilizaran el medio aéreo la cantidad reseñada, puesto que buena parte de ellos utilizaran el Tren de Alta Velocidad y nuestras carreteras, que esperemos estén en mejores condiciones que en la actualidad (LOPEZ LARA, 1988; LOPEZ PEREZ, 1988).

\section{CUADRO I}

PROCEDENCIA DE LOS VISITANTES A LA EXPO'92

\begin{tabular}{|c|c|}
\hline 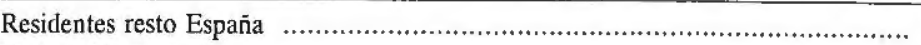 & 5.151 .405 \\
\hline Turistas Nacionales & 917.955 \\
\hline Turistas Zona Sur España & 117.326 \\
\hline Visitantes Específicos & 2.133 .469 \\
\hline TOTAL & 8.320 .155 \\
\hline
\end{tabular}

Fuente: Sociedad Estatal Expo'92. 
En principio, no podemos sacar de lo anterior hipótesis de trabajo muy sólidas. Sin embargo, algún que otro dato es posible rastrear. Los medios de comunicación sevillanos, (ABC. Septiembre 1989), facilitaban la noticia de que durante los ocho meses de la muestra, el Aeropuerto Hispalense registrará una demanda media de 19 aeronaves/hora, a la vez que informaba que el nuevo Edificio Terminal estaba siendo construido para atender unos 4.500 pasajeros/hora punta.

Es evidente que la cifra de aeronaves/hora debe referirse a las previsiones de movimientos de aeronaves en el Aeropuerto de San Pablo, es decir la suma de despeges y aterrizajes, si el concepto de media se ha utilizado de forma correcta.

Las previsiones, hasta aquí recogidas, suponen que durante ocho meses seguidos el Aeropuerto de Sevilla soportará una carga similar a la estival del Aeropuerto de Palma de Mallorca, 450 movimientos diarios, cantidad muy respetable, tanto de aeronaves como de pasajeros, y para las cuales con mucha dificultad, tanto la infraestructura como la organización del espacio aéreo podrá evacuar, si no se toman las medidas necesarias, con tiempo como más adelante comentaremos, que faciliten el tránsito de los mismos.

Si tomamos un tipo de aeronave medio, (DC-9 o B-737), cuya capacidad podemos cifrar en 130 pasajeros, la cantidad de movimientos recogida en el párrafo anterior nos lleva a una cifra que ronda los 8.000.000 de pasajeros, que concuerda bastante con las previsiones realizads por la Sociedad Estatal. Lógicamente no podemos magnificar el hecho, ya que junto a aeronaves de gran capacidad, (cualquier tipo de Jumbo), llegarán aerotaxis y pequeños reactores, aunque a efectos del Control de Tránsito Aéreo, el mismo espacio aéreo ocupa uno y otro, a fin de mantener la mínima separación reglamentaria que garantice la seguridad de los mismos (RCA, 1976).

No debemos olvidar que nos enfrentamos con estimaciones estadísticas, y que el concepto de media es, por demás, vidrioso. Junto a períodos de altísima demanda, para los que es necesario estar preparados, existirán otros de escasa actividad, más aún si tenemos en cuenta que por necesidades, y costumbre, de pasajeros e industria hotelera, más del $80 \%$ de la actividad del transporte aéreo se realiza entre el orto y el ocaso.

Sería muy util contar con algún tipo de estimación sobre la demanda mensual, pero lo recogido por la Expo 92 se refiere al número de visitas al recinto, lo que es muy poco significativo, a nuestros efectos.

Resumiendo, con los datos disponibles, el volumen de movimientos que soportará el Aeropuerto de Sevilla rondará los 400 diarios, lo que supone, para no perder perspectiva, el doble de los que soporta el Aeropuerto de Málaga durante los meses de verano, y Málaga es el quinto Aeropuerto Nacional tanto en movimiento de aeronaves como en el de pasajeros. 


\section{EL ESPACIO AEREO}

Ya hemos dedicado páginas a este aspecto, medio donde se realiza el transporte aéreo de personas y mercancias, (LOPEZ PEREZ, 1981-1986-1988). En esta ocasión es preciso acercarse, más detenidamente a las muy severas restricciones que sufre el espacio que se alza sobre nuestras cabezas, y que desde nuestro punto de vista, será un condicionante de entidad para hacer frente a la demanda previsible de nuestro Aeropuerto.

Para limitar adecuadamente el campo de estudio, el cuadro II nos informa de la superficie de jurisdicción de las diferentes áreas de Control de Tráfico Aéreo Peninsulares, y de la cantidad de espacio sujeta a restricciones de uso por parte de las aeronaves civiles, y el porcentaje que este significa respecto al total, en cada una de ellas.

\section{CUADRO II}

SUPERFICIES DE JURISDICCION Y RESTRINGIDAS POR REGIONES

DE TRAFICO AEREO PENINSULARES (KM.)

\begin{tabular}{|c|c|c|c|}
\hline Denominación & $\begin{array}{c}\text { Superficie } \\
\text { Total }\end{array}$ & $\begin{array}{l}\text { Superficie } \\
\text { Restringida }\end{array}$ & $\%$ \\
\hline 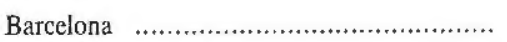 & 265.162 & 39.659 & 14,95 \\
\hline 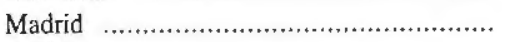 & 434.931 & 52.590 & 12,09 \\
\hline 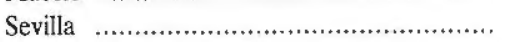 & 175.969 & 90.555 & 51,46 \\
\hline
\end{tabular}

Fuente: A.I.P. España.

El Espacio Aéreo Meridional soporta dentro de sus fronteras el 49,53\% de todas las Areas Peligrosas, Restringidas o Prohibidas de nuestra Península, y mientras que, en el peor de los casos, Madrid sólo tiene restringido menos del $15 \%$ de su área de jurisdicción, Sevilla contabiliza el $51 \%$. No es ocasión de referirnos a las especiales connotaciones que Andalucía tiene dentro de la geoestrategia de OTAN, UEO y correlativamente, C.E.E., (LOPEZ LARA y LOPEZ PEREZ, 1988), pero este es el hecho. Debemos matizar que este espacio aéreo, vetado en la práctica, al tráfico aéreo civil, solo se refiere al establecido de forma permanente o periódica, ya que junto a esto aparecen otras de carácter transitorio que restringen, todavía más, el uso del mismo.

En principio, estas restricciones imponen embudamientos muy estrictos, puesto que por razones obvias, ningún avión civil entra en zonas donde se realizan ejercicios o actividades que significan un peligro potencial para los no participantes en los mismos, y mucho menos el Control del Tráfico Aéreo utiliza estos espacios sin una previa, y estrieta, coordinación. 
Un segundo aspecto es el emplazamiento de las mismas, Gráfico I. Acercarnos al mismo nos informa suficientemente como para ahorrarnos palabras para describirlo. Son especialmente conflictivas las que cubren el Golfo de Cádiz, así como la que se encuentran entre Hinojosa-Bailén-Yeste, las cuales impiden al tráfico volar rutas diferentes, o en el primer caso, a onerosos rodeos para evitarlas. La red de aerovias, Gráfico II, se encuentra, prácticamente, limitada por ellas, y caso insólito, algunas han de utiliarse durante la noche, o en fines de semana, períodos de no actividad de las áreas Peligrosas o Restringidas que atraviesan.
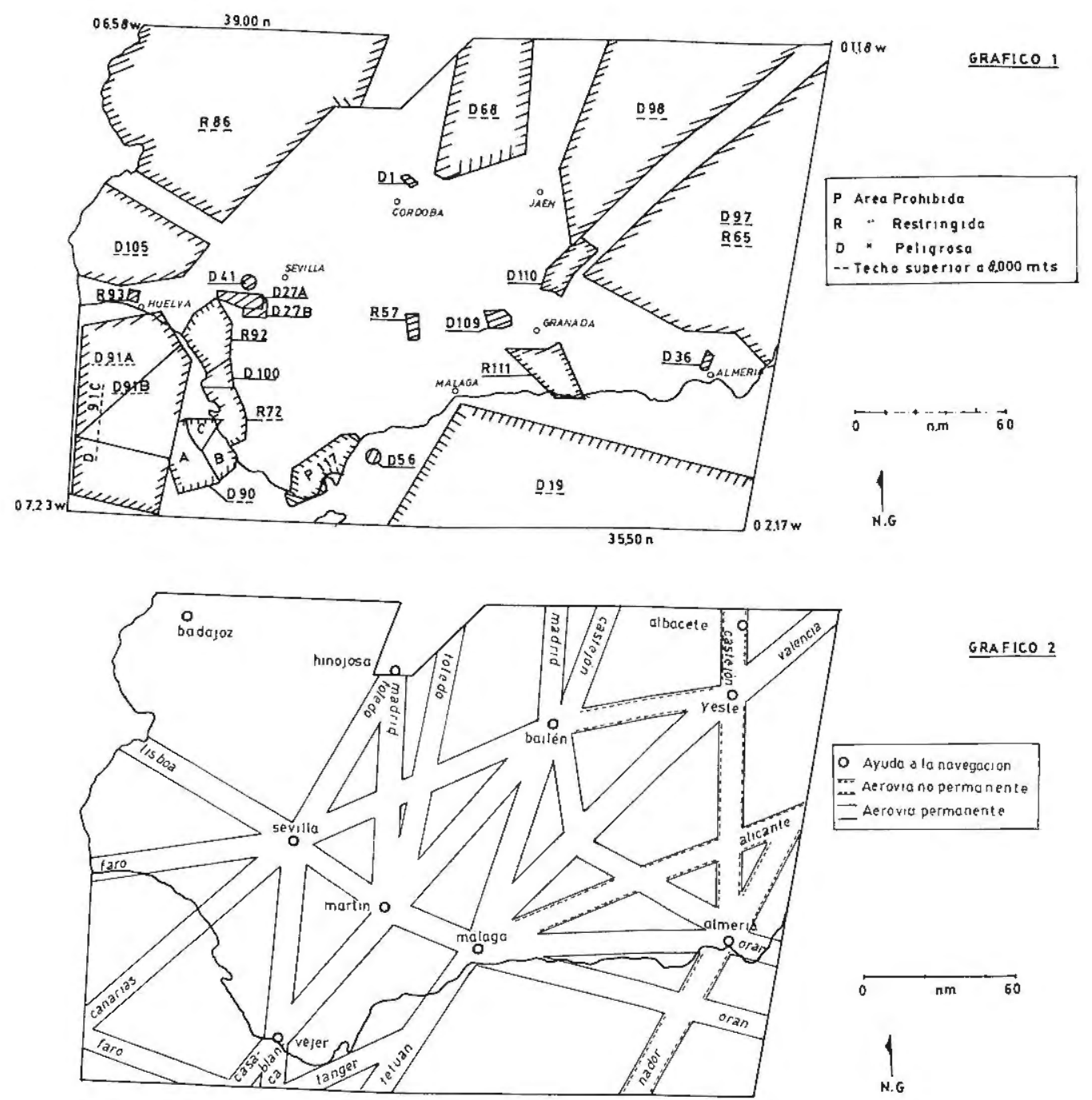
Es palmario el hecho de que una cantidad de tráfico como el que se espera para la Expo 92, necesita espacio aéreo libre de cualquier restricción que permita diversificar rutas y procedimientos que eviten demoras o embudamientos que saturen el sistema, y con la actual estructuración, esta no puede por menos que darse.

\section{PROCEDIMIENTOS Y DOTACION DE RADIOAYUDAS}

La ubicación del aeropuerto, disposición de sus pistas y dotación de radioayudas, se traducen en inconvenientes, salvables si se toman las medidas adecuadas, que relentizarán las operaciones en el Aeropuerto Sevillano.

En efecto, los procedimientos de aproximación al mismo, con pobre visibilidad o techo de nubes bajo, son incompatibles con los que deben realizarse a una Base Aérea cercana. Dicho en otras palabras, mientras que se realiza una maniobra de aproximación a esta, una aeronave que se dirija a Sevilla deberá esperar a que aquella deje de ser conflicto con ella, lo cual se traduce enun tiempo mayor de permanencia en el aire, ya que la seguridad ha de primar sobre cualquier otra consideración. Si esta circunstancia se produce muy frecuentemente, y en teoría así debe ser, las demoras podrán ser de entidad.

El Centro de Control de Sevilla cuenta desde 1983 con un buen equipo de Radar Secundario de Ruta, suficiente para garantizar la vigilancia y proporcionar más fluidez al tráfico aéreo a el encomendado, pero carece hasta el momento de un equipo de Radar Primario, imprescindible para facilitar control a las aeronaves que aterricen o despegen en los distintos aeropuertos y Bases aéreas que se encuentran dentro de su Area de Jurisdicción. Es realmente difícil pensar en evacuar 400 movimientos a un aeropuerto, más el tráfico normal que vuela sobre nuestros cielos, (más de 175.000 movimientos anuales, de los cuales el $60 \%$ tienen como origen o destino Andalucía. Año 1989), sin contar con este Radar Primario. (ANUARIO ESTADISTICO DEL TRANSPORTE AEREO, 1989).

Pero no basta con tener el equipo. Es necesario que esté en funcionamiento un tiempo suficiente para que el personal que deba utilizarlo en misiones de Control de Tránsito Aéreo, se familiarice con el mismo a fin de que en momentos de demanda alta, sea capaz de utilizarlo de forma correcta y adecuada.

\section{CONCLUSIONES}

El compromiso que acarrea la celebración de una Exposición Universal en nuestra ciudad, está significando un cambio sustancial para la misma. La do- 
tación en infraestructura viaria en el entorno ciudadano, el Tren de Alta Velocidad, el propio recinto de la Expo y los pabellones de los diversos países, con su posterior contenido, suponen una inversión cuantiosa. El trabajo de coordinación entre las distintas Administraciones Públicas, (locales, autonómicas, estatales), y la empresa privada, han debido, y deben ser, gigantescos, sin embargo, y estimo que por ser un aspecto poco conocido, excepto por los técnicos en la materia, se ha olvidado que el medio por el cual se acercarán a la Muestra una gran cantidad de visitantes, será por vía aérea.

Este espacio, muchas veces más humanizado que algunas regiones de la tierra, tiene su propia dinámica en cuanto a utilización, reglamentación y competencias, y es absolutamente necesario que, aquí también, se realicen las necesarias coordinaciones, inversiones y proyectos para que sea un elemento más que coadyuve a la feliz realización de la misma.

Es necesario, desde nuestro punto de vista, que la cantidad de espacio aéreo no utilizable por la aviación civil sea el mínimo imprescindible, al menos durante la celebración de la Exposición, para lo cual serán necesarios acuedos entre el Ministerio de Defensa y Transporte, con el tiempo suficiente para que este sea operativo.

En suma, la imagen de Andalucía, y por ende de España, se enfrentan a un reto importante. Nuestro país ha de demostrar que es una nación moderna, y donde los servicios tienen calidad comparable a la de cualquier otra europea. Ello pasa, necesariamente, por unos enlaces aéreos satisfactoriamente rápidos. No solo es importante adecuar un Aeropuerto, que la oferta de plazas aéreas sea ámplia, sino que el medio por donde esta actividad ha de llevarse a cabo, se encuentre suficientemente dotado en cuanto a infraestructura y libre de la mayor cantidad posible de obstáculos, para que aquéllo pueda ser posible.

\section{BIBLIOGRAFIA}

CANO GARCIA, G.: "El transporte aéreo en España». Ariel, Barcelona, 1980. "El Transporte Aéreo en Andalucía», Geografía de Andalucía. (Dir. G. Cano), Vol. VI. Tartessos, Sevilla, 1988.

LOPEZ LARA, E.: «El transporte por carretera en Andalucía», Geografia de Andalucia. (Dir. G. Cano), Vol. VI. Tartessos, Sevilla, 1988.

LOPEZ PEREZ, F.: «Los límites marítimos y aéreos», Geografía de Andalucía. (Dir. G. Cano), Vol. I, Tartessos, Sevilla, 1988.

MINISTERIO DE TRANSPORTE, TURISMO Y COMUNICACIONES: "Aeronautical Information publication , Vol. II, RAC. Madrid, 1987. 